\title{
EDITORIAL
}

\section{AGING FRIENDLY HEALTH SYSTEMS}

\author{
A.M. SANFORD ${ }^{1}$, M. BERG-WEGER ${ }^{1,2}$, J. LUNDY ${ }^{3}$, J.E. MORLEY ${ }^{1}$
}

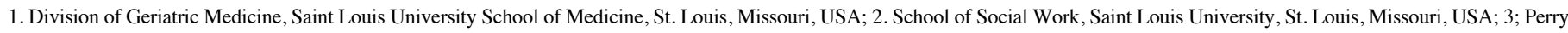

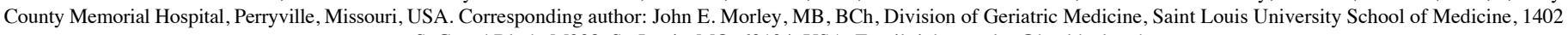
S. Grand Blvd., M238, St. Louis, MO 63104, USA, Email: john.morley@health.slu.edu
\end{abstract}

In 1848 , George Day, in the introduction to his book on aging, wrote he made no apology for the text as physicians did not understand how to care for the diseases of older persons (1). In 1914, Ignatz Leo Nascher introduced the term geriatrics (2). It was Marjory Warren who introduced what was the basis of modern geriatric rehabilitation in 1935 (3). The concept that aggressive rehabilitation for persons with functional problems, could improve outcomes was solidified by Laurence Rubenstein et al (4) with their publication on the success of the Geriatric Evaluation and Management Unit for treating persons with deficits in activities of daily living.

The modern movement in geriatrics has been the recognition that specific geriatric syndromes exist, e.g., sarcopenia, frailty, anorexia of aging and cognitive dysfunction and that early intervention to manage these "modern giants of geriatrics" can delay the aging process and enhance quality of life in older persons (5). This has led to the need to develop personalized medicine for older persons which focuses on developing individualized secondary prevention to prevent functional deterioration (6).

It is now recognized that there is a major shortage of geriatricians to deal with the "Aging Tsunami" (7). This means that the future of high quality care for older persons will require an increased knowledge and focus of primary health professionals. Geriatrics as developed has required an intensive prolonged interface between health professionals and the older person. The primary care physician has 15 minutes or less to interact with the patient. The solution to this problem is to create rapid geriatric screens followed by algorithmic diagnostic and treatment protocols as we have at Saint Louis University (8). These management protocols need to have solid interprofessional support. This approach is the cornerstone of age friendly primary care health systems.

The World Health Organization (WHO) in 2002 was the first to recognize the need to increase responsiveness to older persons problems and enhance primary care interprofessional responses and education to create age-friendly primary care centers (9). This health system is part of the WHO's development of age friendly communities throughout the world to improve the integration of older persons into communities (10). Dementia Friendly communities are a subject of agefriendly communities focusing on the specific needs and inclusion of persons with dementia in the community (11).

The John A. Hartford Foundation has made a concerted effort to enhance hospital care $(12,13)$. They have developed

Received December 28, 2018

Accepted for publication January 4, 2019 a 4M approach as the framework of an age-friendly health system:

- $\mathrm{M}$ - what matters - making the care plan patient orientated

- Medication - reduce polypharmacy and avoid age unfriendly drugs

- Mentation - recognize and treat delirium, depression and dementia

- Mobility - Focus on safe, fall-free walking

In Costa Rica, a geriatric hospital has been developed to provide country wide care for older persons who need specialized geriatric care (14). In Toulouse a day hospital system has been developed for nursing home residents to allow them not to be hospitalized (15).

In Perry County, Missouri, our GWEP program has developed an intensive age-friendly health system including screening for geriatric syndromes with the Rapid Geriatric Assessment as part of the annual Medicare Wellness Visit, Cognitive Stimulation Therapy for persons with dementia (1618), exercise therapy for those with sarcopenia or frequent falls (19), Circle of Friends for lonely people (20), and home visits for persons diagnosed with dementia.

Utilizing the components of the Rapid Geriatric Assessment are an important part of early recognition of geriatric syndromes is an important component of age-friendly health systems to allow secondary prevention. These have been well validated in multiple continents. The FRAIL predicts disability, mortality and gait abnormalities (21-24). Other suitable rapid tests for recognizing frailty are the Edmonton Frail Scale (25, 26) and Rockwood's Clinical Frailty Scale (27). The SARC-F for sarcopenia has been recommended for screening by the International Clinical Practice guidelines for Sarcopenia (28). It is possible that the SARC-F can be improved by adding to it a measurement of calf circumference $(29,30)$ and removing falls from it may work as well (31). The Simplified Nutritional Appetite Scale (SNAQ) is highly predictive of anorexia of aging and future weight low (32-35). The Mini Nutritional Assessment (short form) can be used instead of the SNAQ (3639). The Rapid Cognitive Screen or the Mini-Cog can be used to recognize cognitive dysfunction $(40,41)$.

For nursing homes development of activity programs that enhance function (42) or those that reduce hospitalization (43) are other forms of age friendly health systems.

Age-friendly hospital systems including Acute Care for the Elderly (ACE) units (44), exercise groups (45), Delirium Published online January 12, 2019, http://dx.doi.org/10.1007/s12603-019-1154-5 
Intensive Care Unit (46) and the Help Program (47). There has also been an increase in developing age friendly emergency departments (48).

Overall, this editorial calls for the need to recognize that all health systems need to become age friendly at every level and this needs to be integrated into age friendly communities. Figure 1 gives an overview of the multiple systems that need to be put into place. Given the epidemiological aging imperative, it is essential that all health systems undergo an age-friendly transformation.

In summary, an age friendly health care system is one that focuses on:

- Quality of life for persons as they age

- Recognition of geriatric syndromes to allow targeted interventions can be initiated

- Enhancing functional ability and maintenance of activities of daily living through interdisciplinary care

- Reducing hospitalization readmissions through successfully transitions of care

- Maintaining healthy caregivers and caregiver support

- Developing a patient centered plan that takes into account life expectancy and comorbidities when treating complex medical problems and geriatric syndromes while addressing primary and secondary preventive measures.

\section{Figure 1}

Examples of Age Friendly Health Systems

\begin{tabular}{|c|c|c|}
\hline Age Friendiy & & \begin{tabular}{l}
\multicolumn{1}{c}{ Hospital } \\
Acute Care for Elderly \\
Delirium Intensive Care Unit \\
Physical Exercise Programs \\
Help Program: Daily visitor and \\
mobilisation programs
\end{tabular} \\
\hline 170 & Dentry & $\begin{array}{l}\text { Emergency Department } \\
\text { Rapid Geriatric Assessment } \\
\text { Delirium Assessment } \\
\text { Focused aged referral program }\end{array}$ \\
\hline & & $\begin{array}{l}\text { Health Professional Practice } \\
\text { Annual Medicare Wellness Visit } \\
\text { Advance directives } \\
\text { Fall prevention } \\
\text { Cognitive Stimulation Therapy } \\
\text { Exercise Programs }\end{array}$ \\
\hline $\begin{array}{l}\text { Nursing Homes } \\
\text { Prevention of Unnecessary Hospitalisations } \\
\text { Exercise Programs } \\
\text { Circle of Friends } \\
\text { Cognitive Stimulation Therapy } \\
\text { Meaningful Activities } \\
\text { Excursions } \\
\text { Alzheimer Villages }\end{array}$ & 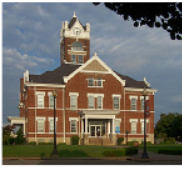 & $\begin{array}{l}\quad \text { Community } \\
\text { Home Visits } \\
\text { Transport } \\
\text { Education } \\
\text { Age Friendly Banking } \\
\text { Age Safe Walk Space } \\
\text { Communal Areas for Seniors } \\
\text { Telehealth }\end{array}$ \\
\hline
\end{tabular}

\section{References}

1. Morley JE. A brief history of geriatrics. J Gerontol A Biol Sci Med Sci 2004;59:1132-1152

2. Chase P. Mitchell K, Morley JE. In the steps of giants: The early geriatrics texts. J Am Geriatr Soc 2000;48:89-94.

3. Matthews DA. Dr. Marjory Warren and the origin of British geriatrics. J Am Geriatr Soc 1984;32:253-258.

4. Rubenstein LZ, Josephson KR, Wieland GD, English PA, Sayre JA, Kane RL. Effectiveness of a geriatric evaluation unit. A randomized clinical trial. N Engl J Med 1984;311:1664-1670.

5. Morley JE. The new geriatric giants. Clin Geriatr Med 2017;33:xi-xii.

6. Morley JE, Vellas B. Patient-centered (P4) Medicine and the older person. J Am Med
Dir Assoc 2017:18:455-459.

7. Morley JE. Geriatricians: The super specialists. J Am Geriatr Soc 2017;65:866-868.

8. Morley JE. Rapid geriatric assessment: Secondary prevention to stop age-associated disability. Clin Geriatr Med 2017;33:431-440.

9. Araujo de Carvalho I, Epping-Jordan J, Pot AM, Kelley E, Toro, N, Thiyagarajan JA, Beard JR. Organizing integrated health-care services to meet older people's needs. Bulletin of the World Health Organization 2017;95:756-763.

10. Beard JR, Officer A, Araujo de Carvalho I, Sadana R, Pot AM, Michel JP, et al. The World report on ageing and health: A policy framework for healthy ageing. Lancet 2016;387:2145-2154

11. Hebert CA, Scales K. Dementia friendly initiatives: A state of the science review. Dementia (London) 2017; Jan 1:doi; 10.1177/1471301217731433. Epub ahead of print.

12. Fulmer T, Mate KS, Berman A. The age-friendly health system imperative. J Am Geriatr Soc 2018;66:22-24.

13. Mate KS, Berman A, Laderman m, Kabcenell A, Fulmer T. Creating age-friendly health systems - a vision for better care of older adults. Healthc (Amst) 2018;6:4-6.

14. Morales-Martinez F. A teaching geriatric hospital. J Nutr Health Aging. 2018; Nov 10 (Epub ahead of print)

15. Laffon de Mazieres C, Romain M, Hermabessiere S, Abellan G, Gerard S, Castex A, et al. An innovative day hospital dedicated to nursing home resident: A descriptive study of 1306 residents referred by their physicians. J Nutr Health Aging 2018;22:1138-1143.

16. Morley JE, Cruz-Oliver D. Cognitive stimulation therapy. J Am Med Dir Assoc 2014;15:689-691.

17. Stewart DB, Berg-Weger M, Tebb S, Sakamoto M, Roselle K, Downing L, et al. Making a difference: A study of cognitive stimulation therapy for persons with dementia. J Gerontol Soc Work 2017;60:300-312.

18. Aguirre E, Woods RT, Spector A, Orrell M. Cognitive stimulation for dementia: A systematic review of the evidence of effectiveness from randomised controlled trials. Ageing Res Rev 2013;12:253-262.

19. Morley JE. F3ALLS approach to preventing falls. J Nutr Health Aging 2018;22:748 750 .

20. Somes J, Donatelli NS. Retrofitting an emergency department to make it geriatric friendly. J Emerg Nurs 2017;43:472-474.

21. Morley JE, Malmstrom TK, Miller DK. A simple frailty questionnaire (FRAIL) predicts outcomes in middle aged African Americans. J Nutr Health Aging 2012;16:601-608.

22. Rouck JE, Malmstrom TK, Morley JE. Initial validation of the Toulouse St. Louis University Mini Falls assessment in older adults. J Nutr Health Aging 2018;22:880884.

23. Kojima G. Quick and simple FRAIL scale predicts incident Activities of Daily Living (ADL) and Instrumental ADL (IADL) disabilities: A systematic review and metaanalysis. J Am Med Dir Assoc 2018;19:1063-1068.

24. Woo J, Yu R, Wong M, Yeung F, Wong M, Lum C. Frailty screening in the community using the FRAIL scale. J Am Med Dir Assoc 2015;16:412-419.

25. Yang L, Jiang Y, Xu S, Bao L, Parker D, Xu X, Li J. Evaluation of frailty status among older people living in urban communities by Edmonton Frail Scale in Wuhu, China: A cross-sectional study. Contemp Nurse 2018;27:1-22.

26. Amabili P, Wozolek A, Noirot I, Roediger L, Senard M, Donneau AF, et al. The Edmonton Frail Scale improves the prediction of 30-day mortality in elderly patients undergoing cardiac surgery: A prospective observational study. J Cardiothorac Vasc Anesth 2018;May 27 doi: 10.1053.j.jvca.2018.05.036 [Epub ahead of print].

27. Ritt M, Schwarz C, Kronawitter V, Delinic A, Bollheimer LC, Gassmann KG Seiber CC. Analysis of Rockwood et al's clinical frailty scale and Fried et al's frailty phenotype as predictors of mortality and other clinical outcomes in older patients who were admitted to a geriatric ward. J Nutr Health Aging 2015;19:1043-1048.

28. Dent E, Morley JE, Cruz-Jentoft AJ, Aria H, Kritchevsky SB, Guralnik J, et al. International clinical practice guidelines for sarcopenia (ICFSR): Screening, diagnosis and management. J Nutr Health Aging 2018;22:1148-1161.

29. Bahat G, Yilmaz O, Kilic C, Oren MM, Karan MA. Performance of SARC-F in regard to sarcopenia definitions, muscle mass and functional measures. J Nutr Health Aging 2018;22:898-903.

30. Bahat G, Oren MM, Yilmaz O, Kilic C, Aydin K, Karan MA. Comparing SARC-F with SARC-CalF to screen sarcopenia in community living older adults. J Nutr Health Aging 2018;22:1034-1038.

31. Woo J, Leung J, Morley JE. Validating the SARC-F: A suitable community screening tool for sarcopenia? J Am Med Dir Assoc 2014;15:630-634.

32. Wilson MM, Thomas DR, Rubenstein LZ, Chibnall FT, Anderson S, Baxi A, et al. Appetite assessment: Simple appetite questionnaire predicts weight loss in community-dwelling adults and nursing home residents. Am J Clin Nut 2005;82:1074-1081.

33. Ilhan B, Bahat G, Oren MM, BKilic C, Durmazoglu S, Karan MA. Reliability and validity of Turkish version of the Simplified Nutritional Appetite Questionnaire (SNAQ). J Nutr Health Aging 2018;22:1039-1044.

34. Wang T, Shen J. Usefulness of Simplified Nutritional Appetite Questionnaire identifies hospitalized older people at risk of worse health outcomes. J Nutr Health Aging 2016;22:911-915. 


\section{THE JOURNAL OF NUTRITION, HEALTH \& AGING@}

35. Pilgrim AL, Baylis D, Jameson KA, Cooper C, Sayer AA, Robinson SM, Roberts HC. Measuring appetite with the Simplified Nutritional Appetite Questionnaire identifies hospitalised older people at risk of worse health outcomes. 2016;20:3-7.

36. Wei K, Thein FS, Nyunt MSZ, Gao Q, Wee SL, Ng TP. Nutritional frailty state transitions in the Singapore Longitudinal Aging study. J Nutr Health Aging 2018;22:1221-1227.

37. Folven K, Biringer E, Abrahamsen JF. Mini nutritional assessment short-form (MNA-SF) predicts institutionalization in an intermediate post-acute care setting. J Nutr Health Aging 2018;22:199-204

38. Donini LM, Marrocco W, Marocco C, Lenzi A. Validity of the self- Mini Nutritional Assessment (Self-MNA) for the evaluation of nutritional risk. A cross-sectional study conducted in general practice. J Nutr Health Aging 2018;22:44-52.

39. Kucukerdonmez O, Navruz Varli S, Koksal E. Comparison of nutritional status in the elderly according to living situations. J Nutr Health Aging 2017;21:25-30.

40. Seitz DP, Chan CC, Newton HT, Gill SS, Herrmann N, Smailagic N, et al. MiniCog for the diagnosis of Alzheimer's disease dementia and other dementias within a primary care setting. Cochrane Database Syst Rev 2018;22;2:CD011415.

41. Malmstrom TK, Voss VB, Cruz-Oliver DM, Cummings-Vaughn LA, Tumosa N, Grossberg GT, Morley JE. The Rapid Cognitive Screen (RCS): A point-ofcare screening for dementia and mild cognitive impairment. J Nutr Health Aging 2015; 19:741-744
42. Morley JE, Philpot CD, Gill D, Berg-Weger M. Meaningful activities in the nursing home. J Am Med Dir Assoc 2014;15:79-81

43. Rantz MJ, Popejoy L, Vogelsmeier A, Galambos C, Alexander G, Flesner M, et al. Successfully reducing hospitalizations of nursing home residents: Results of the Missouri Quality Initiative. J Am Med Dir Assoc 2017;18:960-966.

44. Fox MT, Persaud M, Maimets I, O'Brien K, Brooks D, Tregunno D, Schraa E. Effectiveness of acute geriatric unit care using acute care for elders components: A systematic review and meta-analysis. J Am Geriatr Soc 2012;60:2237-2245.

45. Flaherty JH, Tariq SH, Raghavan S, Bakshi S, Moinuddin A, Morley JE. A model for managing delirious older inpatients. J Am Geriatr Soc 2003;51:1031-1035.

46. Martinez-Velilla N, Casas-Herrero A, Zambom-Ferraresi F, Lopez Saez de Asteasu M, Luci A, Galbete A, et al. Effect of exercise intervention on functional decline in very elderly patients during acute hospitalization: A randomized clinical trial. JAMA Intern Med 2018;Nov 12 doi; 10.1001/jamainternmed.2018.4869. [Epub ahead of print].

47. Hshieh TT, Yang T, Garfaganis SL, Yue J, Inouye SK. Hospital elder life program Systematic review and meta-analysis of effectiveness. Am J Geriatr Psychiatry 2018;26:1015-1033.

48. Pitkala KH. Loneliness in nursing homes. J Am Med Dir Assoc 2016;17:680-681 